\title{
Att vägra mörda sitt själv
}

\author{
Av Jan Beskow
}

Problemet med samhällets psykosociala produktion av lidande har lösts genom att lägga ansvaret på den suicidala personen. Hon vill ju dö! Hon vill ju mörda sitt själv! Att förlägga hoten inom människan har emellertid sedan länge övergivits inom olycksfallspreventionen, som effektiviserats med hjälp av systemteori. I själva verket arbetar den suicidala personen intensivt på att stå emot sina suicidala impulser. Hon vägrar att mörda sitt själv. För att förstå hur detta går till behövs en ökad förståelse för hur självet konstrueras och används. I mötet med vår tids många symboliska hot övergår en del personer från problematisering via personifiering till suicidalisering, hela tiden under alltmer desperata försök att rädda sina liv.

\section{Kroppen vill leva men kognitionerna vet inte alltid hur det ska gå till}

Albert Camus hävdade att livet saknade mål och mening. Slutsatsen i Myten om Sisyfos blev ändå att Sisyfos förmodligen ville leva, ty lusten kommer ur kroppens liv. Faktum är att människan utstår nästan vilken plåga som helst för att få vara kvar i livet. Kroppen vill leva men kognitionerna, dvs varseblivningar, bilder, minnen, tankar, problemlösningar $\mathrm{mm}$, vet inte alltid hur det ska gå till. Suicidalitet handlar om att finna ett sätt att hantera sin smärta och sina förluster så att kroppen ändå kan leva. Livet är större än våra tankar om det.

\section{Ett krossat själv}

En ung psykisk och kroppsligt frisk kvinna utsattes för en ovanligt rå våldtäkt. Under denna kände hon att hon dog psykiskt, blev fullständigt ödelagd. Ödelägga innebär att göra så att något blir helt oanvändbart för människor. Hon kände djup skam och ville inte att någon skulle plågas av att se hennes elände. Det själv hon hade byggt upp sedan hon föddes med alla dess erfarenheter, sche-man och speciella identitetsmarkörer krossades. Genom att dölja sig bakom ett tomt skal kunde hon om än med svårighet fortsätta och genomföra sin utbildning. Om detta inte fungerade skulle hon ta sitt liv. Uppenbarligen hade hon tagit till sig det omgivande samhällets värderingar att en kvinna som utsatts för våldtäkt

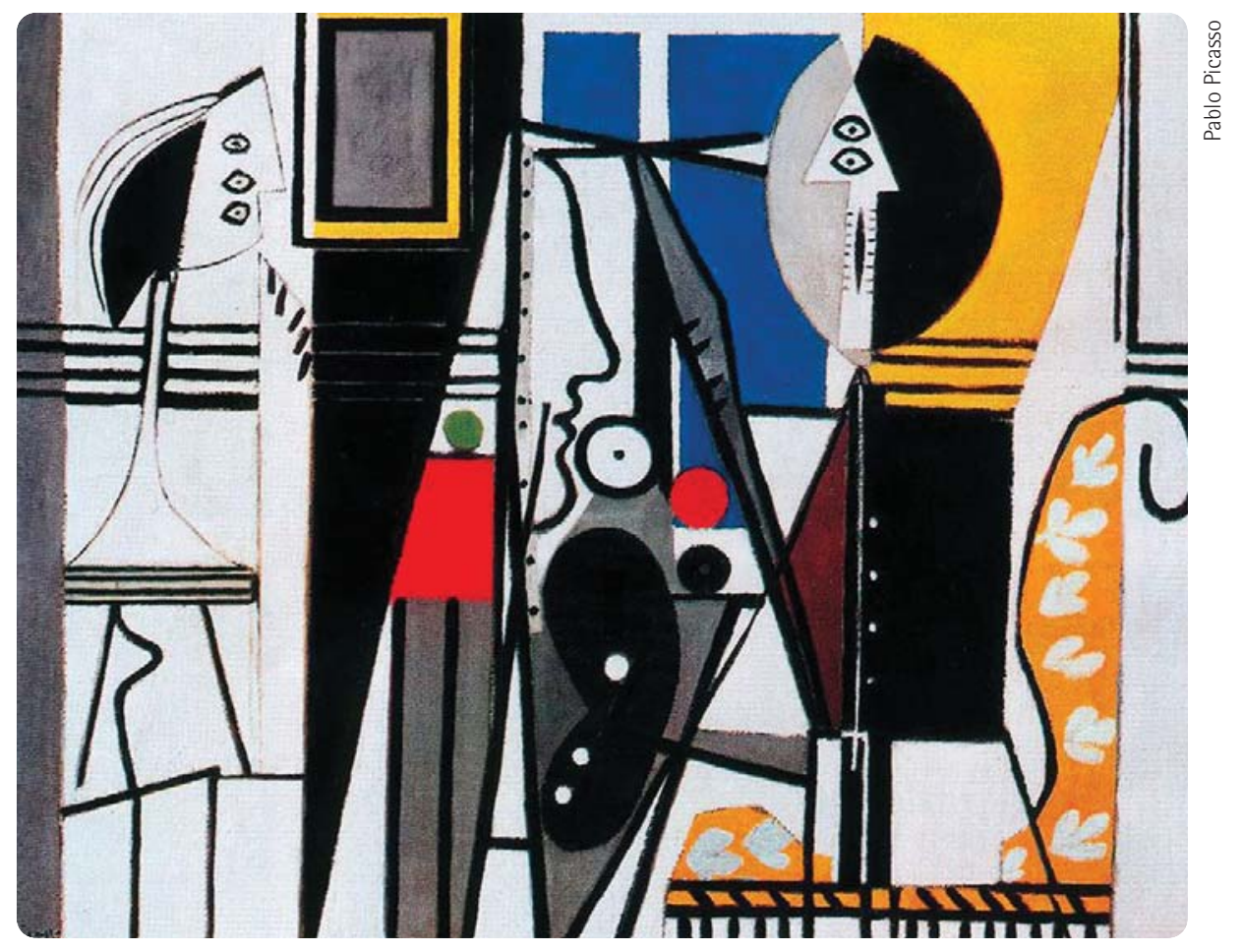

inte bör få finnas längre. Detta väcker flera frågor: Vem är det som dödar och vem är det som dödas? Vem är jag? Jag själv? Självet?

\section{PERSPEKTIV PÅ SJÄLVET}

Var och en av oss har en intuitiv känsla av att finnas till och vara ett aktivt subjekt. Orden jag och själv används dock på växlande sätt. För vårt ändamål räcker det att uppfatta jaget som den aktiva psykologiska principen, den som gör något. En av dess aktiviteter är att jaget ser på sig själv, på mig själv. Självet är således jagets bild av sig själv, sig själv sedd utifrån, således två perspektiv på samma sak. Självbilden eller självuppfattningen kan upplevas på många sätt, t ex som självbild, självkänsla, självvärdering och självförtroende.

Kulturellt. Hur man ska uppfatta självet, teorierna om självet, är mer komplicerade än så. I denna mening är självet en mänsklig uppfinning, som utvecklats i flera steg. Under antik tid beskrevs människans inre liv utan inre dialog utifrån personens kroppshållning, mimik och tal. Ödet styrde människornas liv. Mot slutet av 1400talet fann man att människans viktigaste värde var att hon kunde skapa sig själv. 


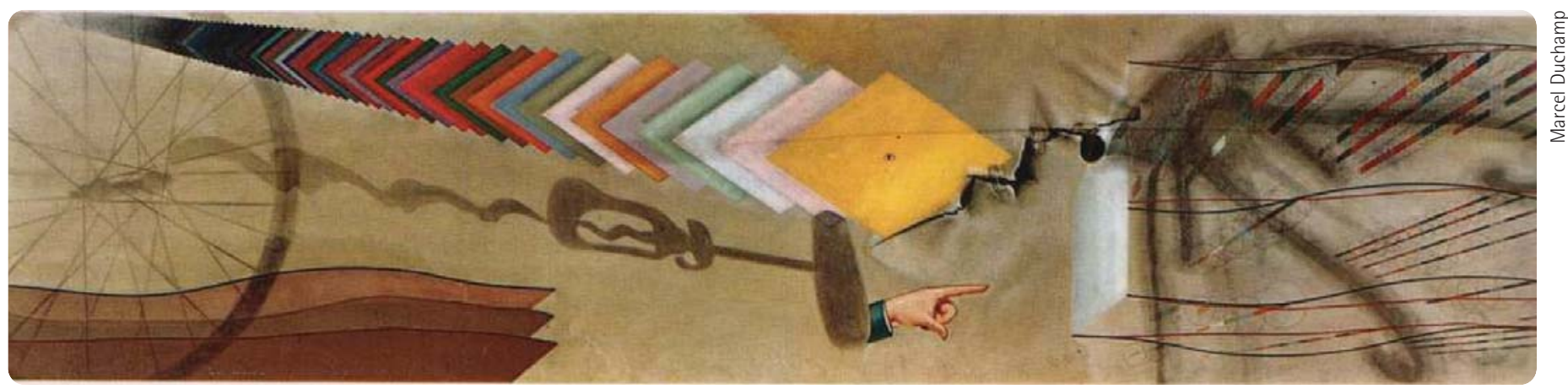

I bildkonst och litteratur har sedan bilden av ett alltmer omfattande själv växt fram. Det inkluderar den tid som flytt (Marcel Proust) och dagens alla små händelser (James Joyce) men som har förlorat sin enhetlighet och blivit alltmer splittrat (Pablo Picasso) och platsberoende (Marcel Duchamp). Självet framstår nu som ett ständigt skapande föränderligt själv i en ständigt föränderlig värld.

Neuropsykologiskt. Var i hjärnan finns då jaget/självet? Svaret är att jaget/självet inte finns. Det består av många processer i hjärnan, samlade till en föreställning med två perspektiv: jag och mig, som båda är kognitiva konstruktioner. Dessa har givetvis ett neurofysiologiskt underlag, men de är inte substanser med fast lokalisation utan produkter av ständigt föränderliga kommunikativa system. Hur sambandet mellan neurofysiologiskt underlag och medvetet själv ser ut vet man inte heller - inte ännu. Hjärnan uppfattas som en orkester utan dirigent.

Ego-tunneln. Jaget/självet är emellertid en för levandet nödvändig kognitiv konstruktion byggd av bilder och ord. Jag/ självet eller egot upplevs subjektivt som en enhet, som ständigt förändrar sig med förändringar i tid och rum. Samtidigt är det omgivet av ett inre rum eller en tunnel, det som Thomas Metzinger kallat egotunnel. Långt fram i denna tunnel skymtar en framtid, som för den friska människan ter sig ljus. Ordet tunnel markerar rörelse till skillnad från begreppet "inre rum" som är statiskt. Denna inre tunnel är min inre bild av den miljö jaget/självet verkar i: "Det är här jag är." Känslan av kontinuitet skapas av de vanor vi skaffar oss under lång tid, framför allt denna ständigt återskapade jag-tunnel. De uppsplittrade isolerade själv som skapas i vår tid är sårbara för destruktiva impulser. Deras kamp för att få leva kvar tillsammans med andra blir ofta tuff.

\section{KONSTRUKTION AV SJÄLVET}

Självet är således konstruerat. Men hur går detta konstruerande till utvecklingspsykologiskt och i vårt vardagsliv.

Från första dagen i detta liv är människan aktör och medskapare av sig själv. Barnet konstruerar bilden av sig själv genom att successivt avgränsa sig allt mer gentemot andra. Sina första upplevelser får barnet på ett dubbelt sätt. När det lägger handen på sitt lår upplever handflatan låret och låret handflatan, double-touch. Dessa fragmenterade upplevelser, the emergent self, sammanför barnet intuitivt till kärnsjälvet så att det vid 7 till 15 månaders ålder upplever ett subjektivt själv. Medvetenhet, d v s att förstå innebörden av något i relation till sina personliga behov och intressen, kräver att barnet kan sätta ord på, verbalisera, sina upplevelser och därmed skapa ett verbalt själv. Först sker detta fragmentariskt sedan insatt i en lång och detaljerad berättelse, ett narrativt själv. Barnet kan därefter lägga till ytterligare två nivåer. Småningom förstår det de strukturer och funktioner som ligger bakom upplevelserna - ett strukturerat själv. Detta kan användas till distans, kritik och skapandet av nya vanor, nya scheman - ett skapande själv.

Strävan efter helhet. Daniel Stern är angelägen att påpeka att detta inte är faser, som börjar och slutar, utan uppkomsten av domäner som finns hela livet.

När man ställs inför ett problem har man behov av att använda sina tidigare, ofta glömda, numera icke medvetna erfarenheter. Detta kan beskrivas med följande modell. Största delen av våra minnen är icke verbaliserbara, andra delar är verbaliserbara. En del av de senare har jaget redan verbaliserat inom sig, en förberedelse för att föra det hon skapat inne i sig ut i den yttre omgivningen, förverkliga det, genom att berätta om det eller göra något.

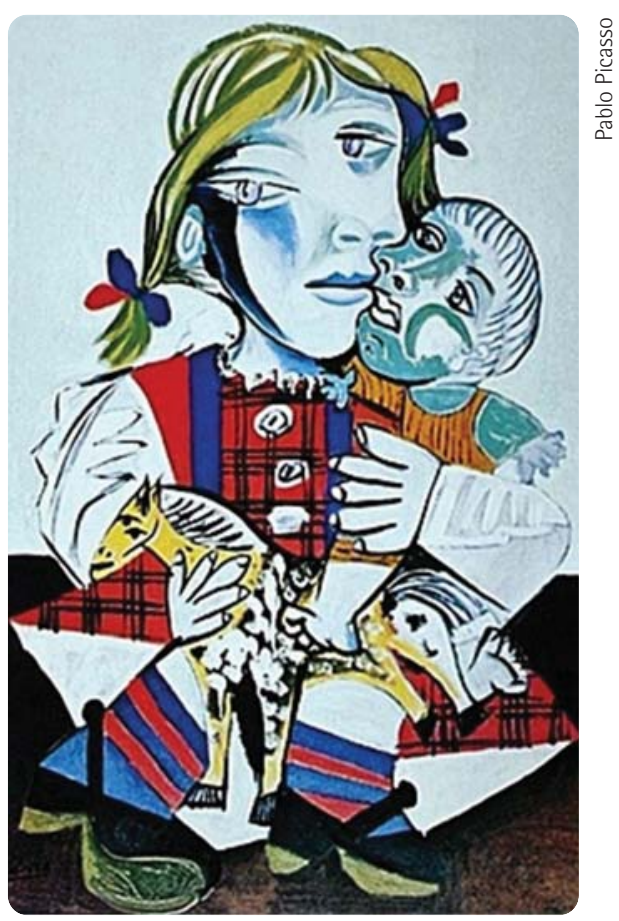


Ingenting i människors värld blir till utan att de skapats inom en enskild människa. Genom att med kognitioner, emotioner, kroppsförnimmelser och beteende skapa väl genomtänkta och genomkända inre verkligheter underlättas och effektiseras skapandet, omskapandet och nyskapandet av världen. När fragmenterade upplevelser sätts in i ett levande sammanhang skapas begriplighet, sammanhang och mening, KASAM. När människan möter lidande framentariseras åter hennes värld och ställer henne inför uppgiften att åter skapa en begriplig och hanterbar helhet.

Denna utvecklings egentliga målsättning är att förflytta beroendet av yttre, men väl inlärda scheman, till självvalda, ännu mer integrerade inre scheman för att kunna styra sig själv inifrån och på så sätt kunna utveckla sig själv och sina talanger. Just detta kan sägas vara vår uppgift på jorden: Att förverkliga de talanger vi har, det bidrag vi kan ge till det kollektiva mänskliga livet.

\section{FÖRSVAR AV SJÄLVET}

För att bekämpa hot mot livet har vi som andra djur utrustats med starka automatiska försvarsreaktioner, som på engelska kallas flight,fight, freeeze/faint, på svenska att fly, kämpa, stelna till och svimma. Vid akut hot kopplas medvetenheten, kognitionerna bort. De är alldeles för långsamma och ställer bara till trassel. Försvaret sker automatiskt på mellanhjärnenivå. Det är oerhört snabbt, kraftfullt, effektivt men ur kognitionernas perspektiv ofta onyanserat. Det märkliga är att dessa primitiva försvarsreaktioner till struktur och funktion i allt väsentligt är likadana när det gäller angrepp av ett lejon på savannen eller ett symboliskt hot i vår tid, t ex ett nedsättande yttrande. Båda ger en aktivitetsökning, en beredskap för flykt eller kamp, vilket kan leda till metaboliskt syndrom, ångest, depression och kronisk stress ända fram till utbrändhet. I vårt differentierade samhälle kommer differentierade kognitioner mer till användning vid problemlösningen.

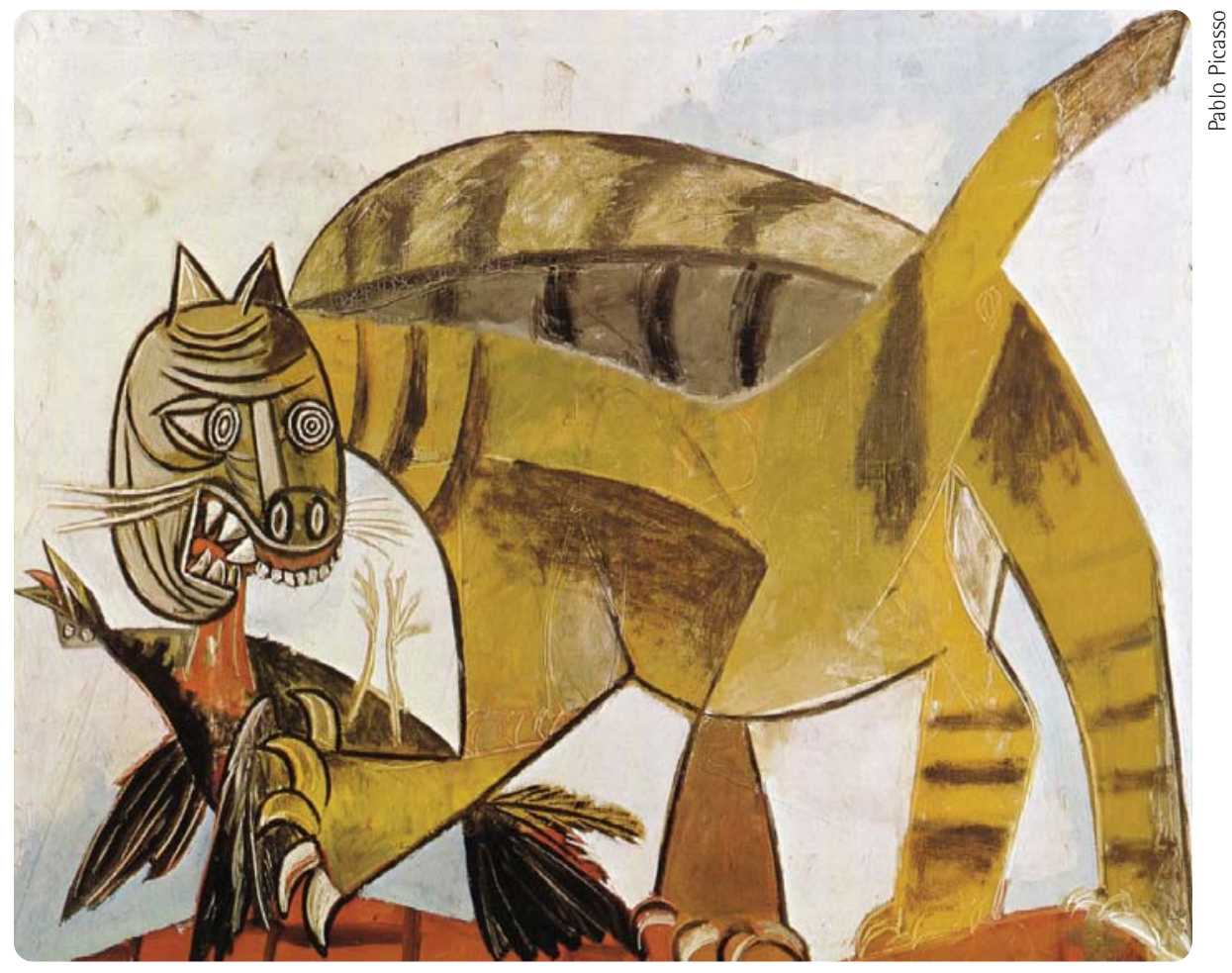

När människor möter det psykosociala lidandet som samhället producerar räcker deras kognitioner inte alltid till. Kampen för att återvinna helheten och leva vidare sker i tre steg: problematisera, personifiera och slutligen suicidalisera.

\section{Problematisera}

Det är konstruktivt att vidga begreppet problem från enbart negativa händelser till livets alla händelser, både positiva och negativa. Båda kräver tydliga, närliggande mål och medveten strategi. I strävan efter snabb återgång till normalitet efter en negativ händelse är en sådan problematisering ett viktigt hjälpmedel. Problemorientering gynnar ett ständigt lärande, vilket är nödvändigt i ett samhälle i ständig förändring. Ett positivt drag i detta förhållningssätt är att man aldrig kan misslyckas. Om den föreslagna lösningen inte fungerar har man bara gjort en ny värdefull erfarenhet - dags att pröva något nytt.

\section{Personifiera}

Av välgång och beröm lär du trygghet och stabilitet. Det är bra. Av besvikelser lär du dig att förstå dig själv och dina begränsningar men de manar också fram ny energi och ny fantasi att utveckla dig själv genom ännu smartare lösningar. Det är därför rimligt att "tacka Gud för sina besvikelser!"

Den person som inte lyckas lösa påträngande problem och återta kontrollen har en tendens att göra en förskjutning av problemet utifrån och in: "Det är jag som är problemet!" Har man fått dåligt betyg på ett prov är det rationellt att rannsaka sig själv och satsa på bättre förberedelser. Alltför ofta hamnar man emellertid i en nedåtgående spiral av oro och ältande av självanklagelser genom att använda destruktiva tankestrategier. Hit hör att ständigt fästa sig vid det negativa, förstora, generalisera och till slut fyllas till brädden av rädsla inför konsekvenserna, den hotande katastrofen när alla skall se vilken bluff jag är. Det är svårt att ändra på detta. Ofta hamnar man därför i allt större förtvivlan. Det öppnar vägen för suicidalisering. 


\section{Suicidalisera}

Normal suicidalitet. Att tänka på suicid är en evolutionärt utvecklad överlevnadsmekanism. Alla gör det då och då. Men den normala suicidaliteten kan bli patologisk och ibland livsfarlig.

Att stå på en balkong tio våningar upp i ett höghus och se långt ut över hav och skog ger en känsla av frihet och glädje. Att sedan snabbt böja sig fram och se ner mot asfalten ger ofta små men tydliga tecken på psykofysiologisk aktivering, hjärtklappning, yrsel och muskelspänningar ofta också med en upplevelse av ångest. Ofta kommer tre tankar i snabb följd: "Tänk om den rasar" (olycksfall).

"Tänkt om jag hoppar!" dvs inte kan stå emot mina suicidala impulser (suicid). Då stiger ångesten ytterligare. Det är en påminnelse om min frihet och mitt ansvar, vilket banar väg för den tredje tanken: "Nej, det gör jag inte."

Vad om händer är en snabb förskjutning av hela medvetandet från den avspända kringsynen till fokus på just den punkt nere på asfalten där döden väntar, ibland tydliggjord genom en bild av min krossade och blödande kropp. Denna perceptionsförändring finns också hos djur och innebär fokus på platsen för faran, vilket möjliggör förstoring, fler detaljer och säkrare bedömning, medan ovidkommande faktorer i omgivningen automatiskt utesluts för att inte störa koncentrationen.

Tankar på suicid kan fungera som en plan $B$, som lättar på den förlamande ångesten och möjliggör fortsatt problemlösning. De leder ofta direkt in mot det viktigaste problemet, det som hotar det psykiska och därmed det fysiska livet. Rädslan för döden ger ny energi åt problemlösningarna och gör mer radikala åtgärder tänkbara. Jämfört med döden är det mesta acceptabelt.

Patologisk suicidalitet. Eftersom suicidalitet vanligen är normal och funktionell blir den avgörande frågan hur man ska veta när den går över till patologi.
Detta sker när personen ältar och oroar sig för suicid så mycket att det blir dysfunktionellt och minskar kraften i problemlösningen. Detta är en viktig varning, ett tecken på börjande kognitiv insufficiens. I den delvis icke medvetna delvis medvetna utvecklingen av en färdig suicidal plan, ett suicidalt modus, har man utgått från att personen vill dö. Det är ju huvudinnehållet i den traditionella definitionen på suicid: att det är medvetet och avsiktligt. Människan förbereder sitt självmord. Hon upplever den psykiska smärtan, skälen att dö, inre bilder av den kommande självmordshandlingen samt ställningstagande till de tre viktiga frågorna: Med vilken metod? Var? När ska det ske? Frågan om När? delas i två skilda avgöranden: Valet och beslutet. Valet innebär att välja döden: "Jag ska ta mitt liv. Någon gång, om tio år, tre månader eller i morgon." Därmed har man skapat förutsättningar för att beslutet kan triggas fram när som helst: "Nu ska det ske!"", varefter själva handlingen omedelbart verkställs.
På detta sätt har man sett utvecklingen av ett suicidalt modus som ett uttryck för personens strävan mot döden, mot självmordet. I själva verket är det tvärtom! Kontakten med suicidala personer lär oss att den suicidala processen framför allt är en våldsam och smärtsamt kamp för att undvika självmordet, för att orka fortsätta leva med sina nära relationer.

Normalt är tankar på självmord en reservutgång, en plan $B$, om den psykiska smärtan blir helt outhärdlig. Ju svårare livet blir ju oftare kommer de tunga tankarna, det känns som ett sug in mot döden, som impulser svåra att stå emot. Förtvivlan över att skiljas från sina anhöriga ökar smärtan. Även här förekommer inre bilder: Gråtande anhöriga runt kistan uttrycker att man är en älskad person. Till sist blir tankarna på suicid tvångsmässiga och ockuperar allt mer av medvetenheten. Sömnen förstörs, personen jagas av mardrömmar. Eftersom all kraft är borta orkar hon ej vårda sina mänskliga relationer. Sexualiteten försvinner. Till sist är allt ensamt, ödsligt, ödelagt.

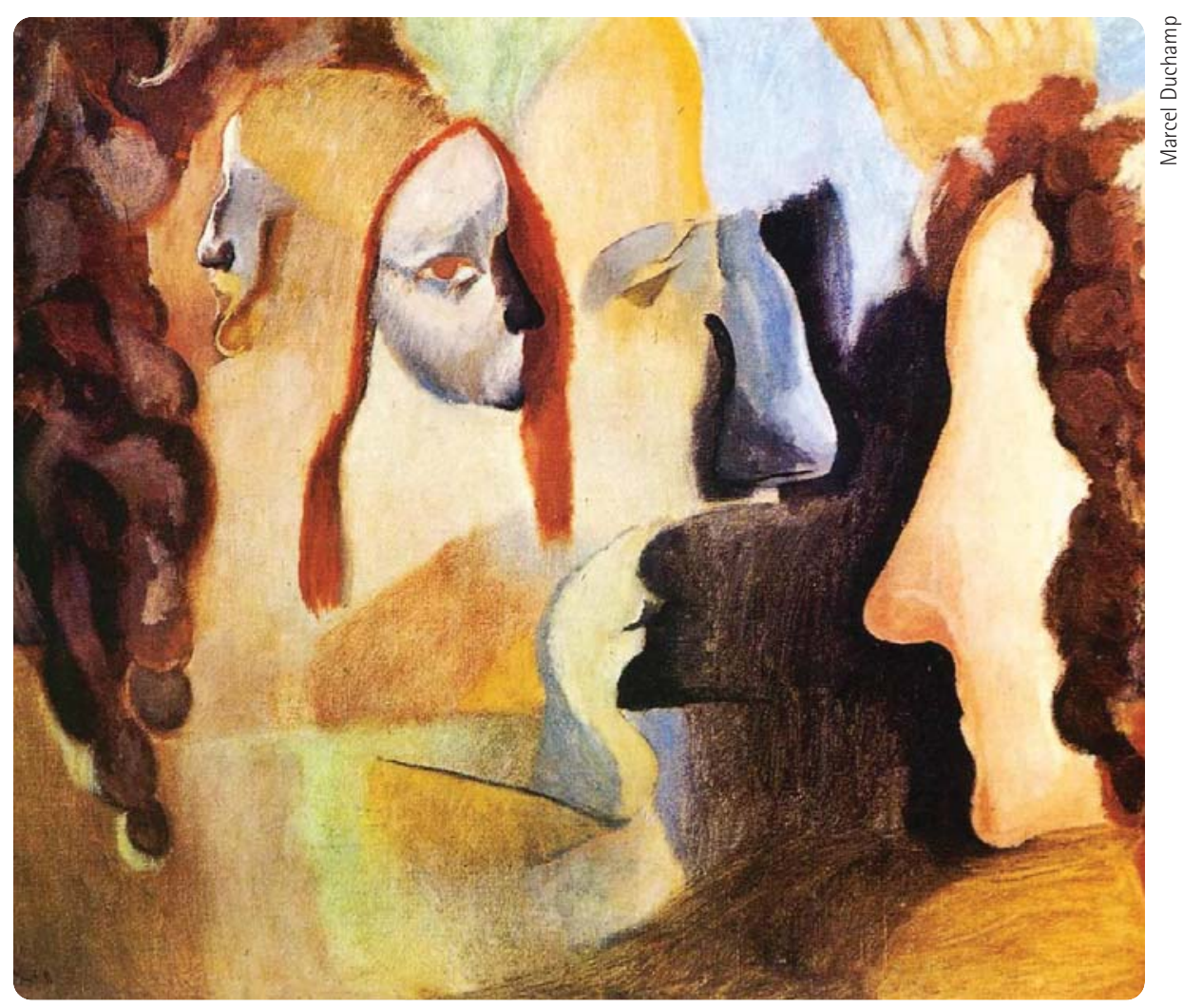


Suicidhandlingen sker ofta i en stund av stark aktivitetsökning ända till kaos, varvid medvetandet splittras, ibland ända till dissociation, och personen tappat greppet om sitt liv - den största kontrollförlusten. En person kan stå i timmar på ett broräcke och kämpa med sig själv bara för att få leva. När alkohol och tabletter verkar kastar sig många på telefonen med en bön om räddning.

Den suicidala personen långa och smärtsamma kamp är inte till för att hon vill mörda sig själv utan därför att hon vägrar att mörda sitt själv. En lång och smärtsam kamp vid ravinens bråddjup, en kamp för att få vara kvar i livet. Inte sällan en stelnande ambivalens mellan att leva eller att i utmattning och förtvivlan ge efter för de suicidala impulserna. Detta är en 180-graders svängning i perspektivet på den suicidala processen, som öppnar för ökad förståelse och nära samarbete med suicidala personer.

\section{KONSEKVENSER FÖR VÅRDEN}

Detta synsätt förändrar vården av suicidala patienter på flera sätt. Terapeuten och den suicidala patienten kan skapa en allians på den grunden att kroppen vill leva även om kognitionerna inte alltid vet hur det skall gå till. Enligt Tvåforskarmetoden ses den suicidala patienten som en respekterad jämlik medarbetare i försöken att lösa hennes mest angelägna problem. På så sätt lyfts patienten på ett påtagligt sätt ur sin isolering och upplever att det finns medmänniskor som bryr sig om henne.

När en sådan oftast gravt traumatiserad person vaknar upp efter ett suicidförsök skall det sitta en medmänniska vid hennes bädd, som med ögon, röst och händer skapar den trygghet hon behöver för att omedelbart bearbeta det trauma som suicidförsöket innebär.

Eftersom suicid oftast begås i ensamhet behöver man lita till patientens egen självreglerande förmåga. Denna behöver stöd i en individuell suicidpreventiv plan, ev. också en individuell suicidriskskala med särskilda kopingstrategier för varje skalsteg, samt förebyggande åtgärder i patientens nätverk.

Vidare måste allmänhetens utbildning i fysisk livräddning kompletteras med psykisk livräddning. Var och en ska träna sig i att tala om existentiella frågor, om liv, död, sexualitet och suicidalitet; känna till grunderna om ångest, depression och suicidalitet; veta hur man talar med personer som funderar på att ta sitt liv och vem som kan hjälpa dem om man inte klarar av det själv.

Till sist måste vi inse att suicidala personer är nyckelpersoner i kampen för att skapa ett samhälle med mindre produktion av psykosocialt lidande än i dag.

Samarbete med patienten. Tankar på suicid är en evolutionärt utvecklad livräddande mekanism, normal och ofta nyttig. Personens strävan under en suicidal process är att överleva, inte att dö. Detta skapar grunden för en god terapeutisk allians samt en betoning av nära, respektfullt samarbete samt utveckling av en individuell suicidpreventiv plan. Den suicidala personen inkluderas i samhället. Sätt stort värde på deras viktiga erfarenheter!

Artikkelen er en redigert versjon av en tidligere publisert artikkel i Psykisk hälsa, mai 2012

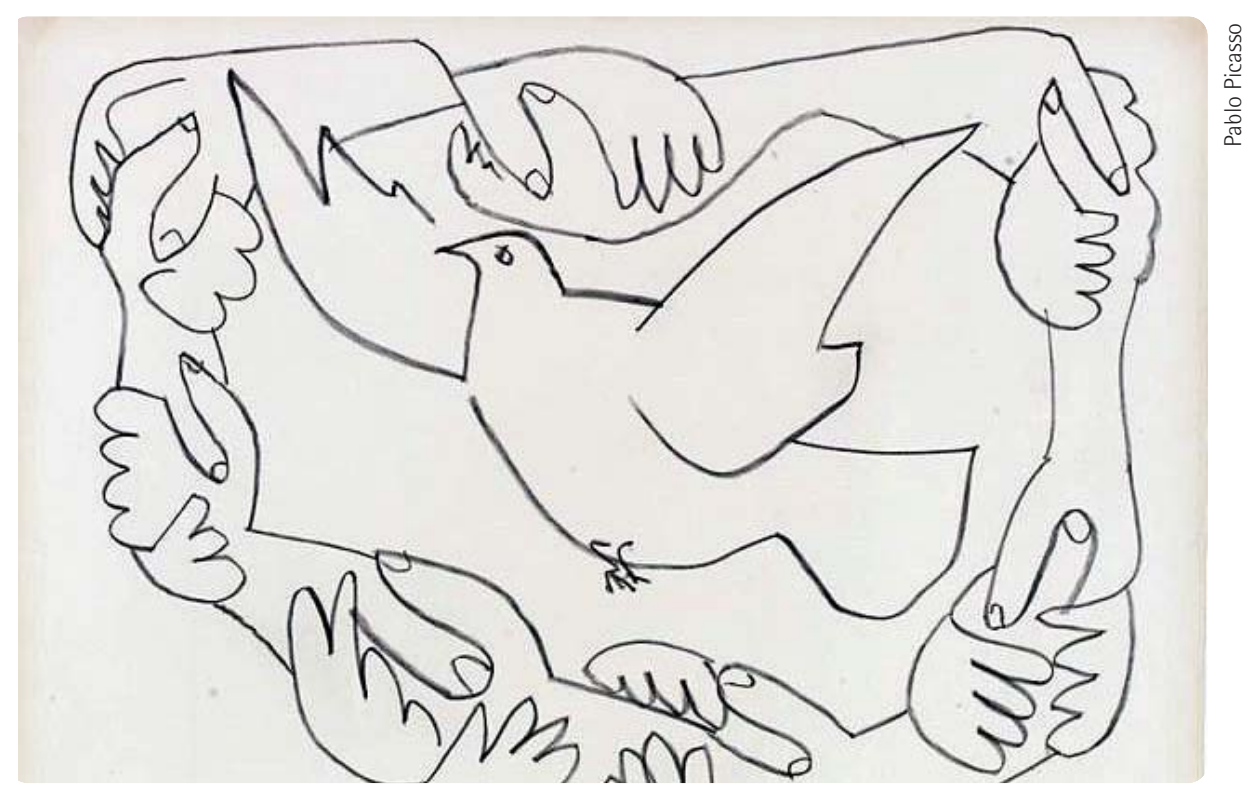

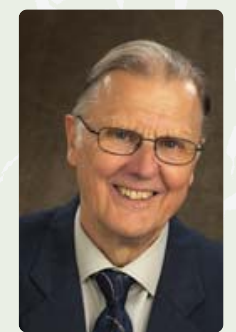

Jan Beskow är professor och läkare, specialist i psykiatri och socialmedicin. Han är f.d.ordf i Suicidprevention i Väst, SPIV, och knuten till Sektionen för psykiatri, Sahlgrenska Akademin i Göteborg. Beskow har arbetat 45 år med suicidprevention.

\section{Lästips}

Beskow, J. Självmord som frihet och tvång. Stockholm: Svenska föreningens för psykisk hälsovård monografiserie nr 39, 1994.

Beskow J., Palm Beskow A. och Ehnvall A. Suicidalitet som problemlösning, olyckshändelse och trauma. Lund: Studentlitteratur, beräknad publicering sept. 2013. - En bred redogörelse för ett nytt sätt att se på suicidalitet.

The Times Extreme survivors. 60 of the World's Most Extreme Survival Stories. London: Times Books 2011.

Stern, D. Ögonblickets psykologi. Om tid och förändring i psykoterapi och vardagsliv.

Stockholm: Natur och Kultur 2005.

Williams, M. Suicide and attempted suicide. Understanding the cry of pain. London: Penguin Books, 2001, 1st edition 1997. A.T. Problem solving deteriorates following mood challenge in formerly depressed patients with a history of suicidal ideation. Journal of Abnormal Psychology, 2005;114: 421-31.
Williams J.M.G., Barnhofer T., Crane C. and Beck, 